\title{
Productivity, Quality and Economics of Tomato (Lycopersicon esculentum Mill.) Cultivation in Aggregate Hydroponics - A Case Study from Coimbatore Region of Tamil Nadu
}

\author{
Asha Joseph* and I. Muthuchamy \\ Department of Soil and Water Conservation Engineering, Agricultural Engineering College and Research Institute, \\ Tamil Nadu Agricultural University, Coimbatore-641 003, Tamil Nadu, India; ashanelppura@rediffmail.com
}

\begin{abstract}
There is a need for low cost, readily available, simple, attractive technologies which can utilize space and water efficiently to increase the productivity in agriculture. Simplified hydroponics is one such option which does not require costly facilities, high running cost and intensive care. This study is an attempt to develop certain low cost aggregate hydroponic techniques for tomato production under naturally ventilated polyhouse located in Precision Farming Development Centre, Tamil Nadu Agricultural University. The experiment was laid out in a factorial randomized block design replicated thrice. Three different hydroponic systems, i.e., tray, trough \& pot and three different media combinations, i.e., cocopeat+gravel+silex stone, cocopeat+pebble+silex stone \& cocopeat+perlite+silex stone, constituted the factors of the treatments. The maximum yield (4.9 kg/plant) was observed for the treatment trough with cocopeat+gravel+silex stone (T4) followed by trough with cocopeat+perlite+silex stone (T6) and trough with cocopeat+pebble+silex stone (T5) with values 4.2 and $3.9 \mathrm{~kg} /$ plant respectively. The highest productivity obtained from the treatment T4 was $245.3 \mathrm{t} / \mathrm{ha}$. The treatment T2 (tray with cocopeat+pebble+silex stone) yielded least $(2.8 \mathrm{~kg} / \mathrm{plant})$ with a productivity of $138.3 \mathrm{t} / \mathrm{ha}$. The highest total soluble solids $\left(12.5^{\circ} \mathrm{brix}\right)$ was recorded for the treatment T4 followed by T6 $\left(10.9^{\circ} \mathrm{brix}\right)$ and $\mathrm{T} 5\left(10.5^{\circ} \mathrm{brix}\right)$ and the lowest $\left(8.3^{\circ} \mathrm{brix}\right)$ was recorded for the treatment T1 (tray with cocopeat+gravel+silex stone. Regarding colour values all hydroponic treatments showed $\mathrm{a}^{*} / \mathrm{b}^{*}$ values greater than 0.95 indicating full maturity. $\mathrm{L}^{*}$ value was also highest for T4 (44.45). The highest (benefit cost) B/C ratio (4.52) was obtained for the same treatment $\mathrm{T} 4$. All hydroponic treatment worked out B/C ratio greater than 1.5. Regarding productivity, quality and economics, the treatment $\mathrm{T} 4$ trough with cocopeat+gravel+silex stone (in the ratio $2: 1: 1 \mathrm{v} / \mathrm{v}$ ) performed best and can be adopted for commercial production of tomato.
\end{abstract}

Keywords: Cocopeat, Gravel, Hydroponics, Media, Perlite, Pebble, Silex Stone

\section{Introduction}

Tomato is an annual horticultural fruit with a worldwide distribution and high economic value. Its consumption benefits human health because of its high antioxidant compounds content. There are food safety concerns in many countries. Soilless vegetable production is one solution to eliminate pest and disease and heavy metal contamination. Excessive and indiscriminate use of pesticides for vegetable cultivation not only increases the cost of production but also results in many human health problems and environmental pollution. As per World Health Organization approximately seven million people died of air pollution around the world in 2012.

In addition, conventional crop growing in soil (open field agriculture) is somewhat difficult as it involves large

${ }^{*}$ Author for correspondence 
space, lot of labour and large volume of water. Moreover, in some places like metropolitan areas, soil is not available for crop cultivation at all, while in some areas, there is a scarcity of fertile cultivable lands due to their unfavorable geographical or topographical conditions. With the reduction in ground water levels, reduction in arable land, increment in urbanization and soil erosion due to deforestation, the state may face an acute food crisis in the near future. Under such circumstances, in the near future it will become impossible to feed the entire growing population using open field system of agricultural production only. Naturally, soilless culture in which plants are raised without soil is becoming more relevant in the present scenario, to cope-up with these challenges.

Improved space and water conserving methods of food production under soil-less culture have recorded some promising results all over the world. The future consumers will demand higher quality resources ${ }^{1}$. The combination greenhouse hydroponics is a clear example of how horticulture could meet the objectives of a sustainable horticulture, with more efficient use of inputs: water and fertilizers ${ }^{2}$. Hydroponics is highly productive and fit for automation.

The selection of growing system and media depends on availability, ease of use, cost and environmental aspects. The hydroponic media selected should be inert and have desirable properties like good aeration, porosity and water holding capacity to enhance the growth and development of plants.

Hence a study was contemplated to develop suitable hydroponic techniques with the following specific objectives 1 . To develop efficient aggregate hydroponic systems in a naturally ventilated polyhouse for sustainable production of tomato, 2. To assess the productivity of tomato crop and quality of fruits raised under such systems, 3 . To find out the cost economics of tomato cultivation using the above developed aggregate hydroponic systems.

\section{Materials and Methods}

\subsection{Location and Climate}

The experiment was conducted in the small Low Cost Naturally ventilated Polyhouse located in the PFDC research and demonstration plot (NA5) situated in the eastern block farm of Tamil Nadu Agricultural University (TNAU), Coimbatore during April, 2013 to August, 2013. The naturally ventilated poly house was made of
200 micron UV stabilized LDPE sheet. The length, width and height of the poly house were $14 \times 4 \times 4 \mathrm{~m}$. The area is located at $11^{\circ} \mathrm{N}$ latitude and $77^{\circ} \mathrm{E}$ longitudes with an altitude of $426 \mathrm{~m}$ above the mean sea level. The mean annual rainfall is $723.24 \mathrm{~mm}$ of which $59.9 \%$ during North East monsoon. The maximum and minimum temperature is between $42^{\circ} \mathrm{C}$ in March April to $21.4^{\circ} \mathrm{C}$ in DecemberJanuary.

\subsection{Growing System, Media and Irrigation System Design}

\subsubsection{Growing System}

The different growing systems designed for this particular study were tray, trough and pot systems. Plastic trays were of size $0.6 \mathrm{mx} 0.45 \mathrm{mx} 0.20 \mathrm{~m}$. Troughs of size of $300 \times 20$ $\mathrm{x} 45 \mathrm{~cm}$ and inner sides firmly attached with 750 micron HDPE black polyfilm which is firmly fixed to the GI frame with bolts and screws were specifically designed for soilless trial. The cylindrical plastic pots of size $30 \times 30 \mathrm{~cm}$ were utilized. Totally 18 plastic tray, 9 troughs and 54 pots were arranged inside the polyhouse. The container not only has an effect on plant development, but also on production costs and cultural practices. Polythene bags are commonly used in Florida to produce various greenhouse crops ${ }^{3}$.

\subsubsection{Growing Media}

Three different inert growing media combinations were used for the experiment. The aggregates gravel, pebble and synthetic perlite were layered with cocopeat and silex stone to form the different media combinations. The media was constituted with $50 \%$ (by volume) coco peat as top layer and silex stone (25\%) as the bottom layer in each case with middle layer substituted either with sand, gravel or perlite $(25 \%)$.

Cocopeat is considered as a good growing media component with acceptable $\mathrm{pH}$, electrical conductivity and other chemical attributes. But it has been recognized to have high water holding capacity which causes poor air-water relationship, leading to low aeration within the medium, thus affecting the oxygen diffusion to the roots. This lacuna can be overcome by incorporation of coarser materials into cocopeat which could improve the aeration status of the media. This had been suggested by previous researchers like Bunt ${ }^{4}$, Awang et al. ${ }^{5}$. A coarser medium can be used at a shallower level to ensure good drainage 
and aeration. Perlite is also one possible coarser material which could be used to improve the air-water relationship of cocopeat ${ }^{6}$.

Coir pith briquettes marketed in the trade name of cocopeat $(\mathrm{EC}<0.5 \mathrm{ds} / \mathrm{m})$ was used for the study. Silex is a commercial term for flint. This is a relatively high silica $\left(>85 \% \mathrm{SiO}_{2}\right)$ rock composed of microcrystalline quartz, with calcite. Silex stone $(0.3-0.5 \mathrm{~cm})$ is a good soil conditioner and can hold water and consolidate the substrate. Gravel $(0.5-1 \mathrm{~cm})$ and pebbles $(1-2 \mathrm{~cm})$ of cheap and locally available was used for the study. The waste gravel from crushing industry and waste pebble from sand sieving was utilized for the experiment.

\subsubsection{Irrigation System}

Hydroponic techniques are found successful only when high quality water is used for irrigation $(\mathrm{EC}<1 \mathrm{ds} / \mathrm{m})$. Nutrient solution was loaded in $200 \mathrm{~L}$ capacity tanks and irrigation was given by $5 \mathrm{~mm}$ micro tube drip emitters connected to $16 \mathrm{~mm}$ diameter LLDPE lateral pipes with individual taps to control the flow. Along the laterals, micro tubes of $2 \mathrm{~L} \mathrm{hr}{ }^{-1}$ were fixed at a spacing of $45 \mathrm{~cm}$. Each system was provided with a drainage tube of dia $2.5 \mathrm{~cm}$ at $1.5 \mathrm{~cm}$ above the bottom.

\subsection{Crop and Variety}

As tomato was the first crop produced by hydroponics and has always a vibrant market potential in domestic market, the hybrid tomato (COTH 3) developed by TNAU was chosen for the study. The duration of the crop is 150 days and the fruit size is medium. Spacing allotted was $45 \mathrm{x} 45 \mathrm{~cm}$.

\subsection{Experimental Design}

The experiment was designed under Factorial Randomized Block Design with the treatments as the soilless media combinations and the growing systems. Three growing systems and three media combinations were tested and replicated thrice.

\subsubsection{Details of the Treatments}

Two factors: 1 . Growing systems (3 types)

2. Growing media (3 types of combination media)

T1: Tray system +coco peat $(50 \%)+$ gravel $(25 \%)+$ Silex stone $(25 \% \mathrm{v} / \mathrm{v})$
T2: Tray system + coco peat $(50 \%)+$ pebbles $(25 \%)+$ Silex stone (25\%)

T3: Tray system + coco peat $(50 \%)+$ perlite $(25 \%)+$ Silex stone (25\%)

T4: Trough system + coco peat $(50 \%)+$ gravel $(25 \%)$ + Silex stone $(25 \%)$

T5: Trough system + coco peat $(50 \%)+$ pebbles $(25 \%)$ + Silex stone $(25 \%)$

T6: Trough system + coco peat $(50 \%)+$ perlite $(25 \%)$ + Silex stone $(25 \%)$

T7: Pot system + coco peat $(50 \%)+$ gravel $(25 \%)+$ Silex stone $(25 \%)$

T8: Pot system + coco peat $(50 \%)+$ pebbles $(25 \%)+$ Silex stone $(25 \%)$

T9: Pot system + coco peat $(50 \%)+$ perlite $(25 \%)+$ Silex stone $(25 \%)$

In all the treatments balanced hydroponic nutrients marketed as 'grow' and 'bloom' purchased from Institute of Simplified Hydroponics, Bangalore was supplied regularly through drip micro tube irrigation.

\subsection{Hydroponic Nutrient Irrigation Scheduling}

The nutrient solution should be applied at a rate to fully wet the growing medium and cause some drainage since the substrate used have a high degree of porosity that facilitate this requirement. The growing medium was not flooded with solution as this would force the exclusion of air and have detrimental effects. Proper irrigation was indicated by a small, but a continuous drainage ${ }^{7}$. Accordingly the following nutrient irrigation scheduling was arrived at after a few experiments. It was always ensured that a film of water was maintained at the bottom. The nutrient irrigation scheduling details of tomato were presented in Table 1. Over a long period of time, deposition of nutrient salts in the growing medium occurs, which may cause an imbalance in the nutrient supply. Hence every 1-4 weeks flushed the whole system out with plain water. The final ppm values of the hydroponic nutrient solution used at different growth stages are given in Table 2.

\subsection{Data Collection and Data Analysis}

Three plants from each treatment was selected at random and tagged for observation on yield and quality characters. The average yield of fruits per plant was worked out which was converted into $\mathrm{tha}^{-1}$. The data were subjected 
to statistical analysis of Factorial RBD using the statistical software 'Aggress'.

Economics was worked out using the prevailing market prices of structural components, cost of soilless media, cost of cultivation and revenue. Gross return (revenue) was calculated by multiplying the fruit yield with average

Table 1. Hydroponic nutrient solution scheduling at different growth stages

\begin{tabular}{lccc}
\hline Crop stage & $\begin{array}{c}\text { Qty. applied/ } \\
\text { plant/day } \\
\text { (L) }\end{array}$ & $\begin{array}{c}\text { Duration } \\
\text { of Irrgn. } \\
\text { (Min) }\end{array}$ & $\begin{array}{c}\text { Total qty. } \\
\text { applied/ } \\
\text { plant/stage (L) }\end{array}$ \\
\hline $\begin{array}{l}\text { 1-28 days } \\
\text { (Nursery) }\end{array}$ & 0.25 & 15 & 7.0 \\
$\begin{array}{l}\text { 29-43 days } \\
\text { (Vegetative) }\end{array}$ & 0.50 & 30 & 7.5 \\
$\begin{array}{l}\text { 44-88 days } \\
\text { (flowering) }\end{array}$ & 1.0 & 60 & 45 \\
$\begin{array}{l}\text { 89-148 days } \\
\text { (Fruiting) }\end{array}$ & 1.5 & 90 & 90 \\
$\begin{array}{l}\text { 149-178 days } \\
\text { (Fruiting) }\end{array}$ & 1.0 & 60 & 30 \\
& Total for 178 days & & $179.5=180$ \\
& & & L/plant \\
\hline $\begin{array}{l}\text { Qty-Quantity, Irrgn-Irrigation } \\
\text { (1.0 }\end{array}$ & &
\end{tabular}

market price. The poly house was constructed with a floor area of $56 \mathrm{~m}^{2}(14 \mathrm{~m} \mathrm{x} 4 \mathrm{~m})$ and can accommodate maximum of 277 plants.

For fruit quality analysis of tomato, colour values and total soluble solids (TSS) were measured. Fruit colour of freshly harvested fruits of selected plants were measured using Hunter lab Color flex Colour meter using the $\mathrm{L}^{*}, \mathrm{a}^{*}$, $\mathrm{b}^{*}$ (Non-destructive) method. A hand refractometer was used for the measurement of TSS and the mean values were expressed in degree Brix.

\section{Results and Discussion}

\subsection{Fruit Yield and Productivity}

The yield data is presented in Table 3 and Figure 1 The maximum yield (4.9 kg/plant) was observed for the treatment trough with cocopeat+gravel+silex stone (T4) followed by trough with cocopeat+perlite+silex stone (T6) and trough with cocopeat+pebble+silex stone (T5) with values 4.2 and $3.9 \mathrm{~kg} /$ plant respectively. The average productivity obtained for the treatment T4 was $245.3 \mathrm{t} /$ ha. The treatment T2 (tray with cocopeat+pebble+silex stone) yielded least $(2.8 \mathrm{~kg} / \mathrm{plant})$ with a productivity of

Table 2. ppm values of grow and bloom nutrient solutions used for tomato at growing stage

\begin{tabular}{|c|c|c|c|c|c|}
\hline Elements & $\begin{array}{c}\text { Grow }(\mathrm{mg} / \mathrm{l}) \\
1-28 \text { days }\end{array}$ & $\begin{array}{l}\text { Grow }(\mathrm{mg} / \mathrm{l}) \\
29-53 \text { days }\end{array}$ & $\begin{array}{c}\text { Bloom }(\mathrm{mg} / \mathrm{l}) \\
54-88 \text { days }\end{array}$ & $\begin{array}{c}\text { Bloom }(\mathrm{mg} / \mathrm{l}) \\
89-148 \text { days }\end{array}$ & $\begin{array}{l}\text { Bloom }(\mathrm{mg} / \mathrm{l}) \\
149-178 \text { days }\end{array}$ \\
\hline $\mathrm{N}(\mathrm{NO} 3-)$ & 71.65 & 143.3 & 167.13 & 260.19 & 278.57 \\
\hline K & 106.94 & 213.88 & 385.71 & 600.43 & 642.86 \\
\hline $\mathrm{P}$ & 13.85 & 27.7 & 77.14 & 120.09 & 128.57 \\
\hline $\mathrm{Mg}$ & 13.85 & 27.7 & 38.57 & 60.04 & 64.29 \\
\hline $\mathrm{Ca}$ & 47.69 & 95.38 & 128.57 & 200.14 & 214.29 \\
\hline $\mathrm{S}$ & 18.28 & 36.56 & 93.76 & 145.96 & 156.27 \\
\hline $\mathrm{Fe}$ & 0.92 & 1.84 & 2.57 & 4.0 & 4.29 \\
\hline $\mathrm{Zn}$ & 0.05 & 0.1 & 0.13 & 0.2 & 0.21 \\
\hline B & 0.23 & 0.46 & 0.64 & 1.0 & 1.07 \\
\hline $\mathrm{Cu}$ & 0.02 & 0.04 & 0.06 & 0.1 & 0.11 \\
\hline Mo & 0.02 & 0.04 & 0.06 & 0.1 & 0.11 \\
\hline $\mathrm{Na}$ & -- & & & & \\
\hline $\mathrm{Si}$ & -- & & & & \\
\hline $\mathrm{Cl}$ & -- & & & & \\
\hline $\mathrm{Mn}$ & 0.23 & 0.46 & 0.64 & 1.0 & 1.07 \\
\hline $\mathrm{N}(\mathrm{NH} 4+)$ & 6.27 & 12.54 & 11.41 & 17.77 & 19.02 \\
\hline Final EC value & $0.6 \mathrm{ds} / \mathrm{m}$ & $1.2 \mathrm{ds} / \mathrm{m}$ & $1.8 \mathrm{ds} / \mathrm{m}$ & $2.8 \mathrm{ds} / \mathrm{m}$ & $3.0 \mathrm{ds} / \mathrm{m}$ \\
\hline
\end{tabular}


138.3 $\mathrm{t} / \mathrm{ha}$. The three pot growing media showed medium performance in terms of yield (3.7, 3.2 and $3.4 \mathrm{~kg} /$ plant). However all hydroponic treatments showed high productivity ( $>100 \mathrm{t} / \mathrm{ha})$. The fruit yield and hence productivity was significant at $5 \%$ level for different growing system, media and interaction comparison. Soilless cultivation under naturally ventilated polyhouse stimulated the plant growth and hastened the flowering in tomato, resulted

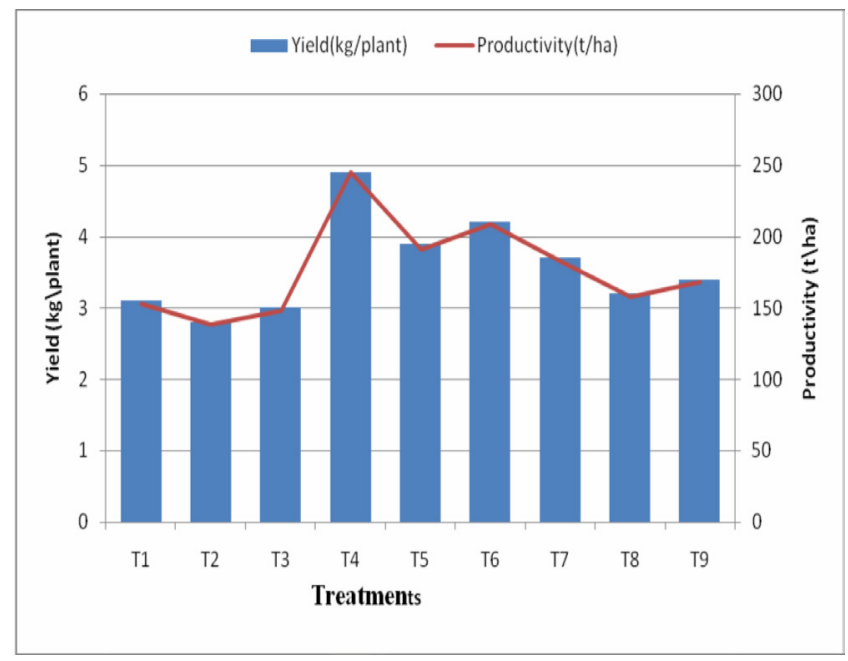

Figure 1. Yield and productivity of tomato crop as influenced by different treatments. enhanced yield attributes in tomato. This increase in the yield attributes was probably associated with the conservation of moisture and improved microclimate both beneath and above the soilless surface. Because of quicker root development of tomato in coir was caused consequently better yield ${ }^{8}$. Strawberry (Fragaria Xananassa Duchense) had grown in coir better than in perlite9. Use of local gravel for the hydroponic cultivation of tomato produced results similar to those with imported perlite ${ }^{10}$.

The substrate physical properties viz. total porosity, water holding capacity and air filled pore space (AFP) are not only functions of the substrate material but also the size and shape of the containers in which they are placed. In general as the container height decreases, the water-filled pore space and the water-holding capacity (as a function of volume) increases and the air-filled pore space decreases. The media combination of cocopeat + gravel + silex stone exhibited higher water holding capacity and lower air filled pore space than the other two media combinations. Lower air filled porosity is required for plants grown in containers. Raviv and Lieth (2008) reported that most media and mixes have an air filled porosity of 10-30 percent. In this study cocopeat+gravel+ silex stone combination have lower air filled porosity

Table 3. Effect of growing system and media on fruit yield and productivity of tomato

\begin{tabular}{|c|c|c|c|}
\hline \multicolumn{2}{|c|}{ Treatment } & $\begin{array}{l}\text { Total Yield } \\
\text { (kg/plant) }\end{array}$ & $\begin{array}{c}\text { Productivity } \\
\text { (t/ha) }\end{array}$ \\
\hline \multicolumn{2}{|c|}{ T1-Tray+cocopeat+gravel+silex stone } & 3.1 & 153.1 \\
\hline \multicolumn{2}{|c|}{ T2-Tray+cocopeat+pebble+silex stone } & 2.8 & 138.3 \\
\hline \multicolumn{2}{|c|}{ T3-Tray+cocopeat+perlite+silex stone } & 3.0 & 148.1 \\
\hline \multicolumn{2}{|c|}{ T4-Trough+cocopeat+gravel+silex stone } & 4.9 & 245.3 \\
\hline \multicolumn{2}{|c|}{ T5-Trough+cocopeat+pebble + silex stone } & 3.9 & 190.9 \\
\hline \multicolumn{2}{|c|}{ T6-Trough+cocopeat + perlite+silex stone } & 4.2 & 209.0 \\
\hline \multicolumn{2}{|c|}{ T7-pot+cocopeat+ gravel+ silex stone } & 3.7 & 182.7 \\
\hline \multicolumn{2}{|c|}{ T8-pot+cocopeat+pebble + silex stone } & 3.2 & 158.0 \\
\hline \multicolumn{2}{|c|}{ T9-pot+cocopeat+perlite + silex stone } & 3.4 & 167.9 \\
\hline \multicolumn{2}{|l|}{ Mean } & 3.6 & 177.0 \\
\hline \multirow[t]{2}{*}{ G } & SEd & 0.07 & 3.50 \\
\hline & $\mathrm{CD}(0.05)$ & 0.15 & 7.42 \\
\hline \multirow[t]{2}{*}{ M } & SEd & 0.07 & 3.50 \\
\hline & $\mathrm{CD}(0.05)$ & 0.15 & 7.42 \\
\hline \multirow[t]{2}{*}{ GXM } & SEd & 0.12 & 6.06 \\
\hline & $\mathrm{CD}(0.05)$ & 0.26 & 12.85 \\
\hline
\end{tabular}

G-Growing system, M-media, GXM-Interaction, t/ha-tons/hectare 
(21.05\%) than cocopeat+perlite+silexstone (23.95\%) and cocopeat+pebble+silexstone (30.1\%). Regarding water holding capacity, though cocopeat+perlite+silex stone have higher water holding capacity (58.68\%) than cocopeat+ gravel+silex stone $(52.63 \%)$ and cocopeat+pebble+silex stone(45.8\%), water in perlite based media is retained only in the surface cavities of perlite. Hence plants grown in this media did not perform well as water availability was lesser than the other two media. Trough possessing larger area $\left(1.35 \mathrm{~m}^{2}\right)$ than tray $\left(0.27 \mathrm{~m}^{2}\right)$ and pot $\left(0.28 \mathrm{~m}^{2}\right)$ has helped in producing longer roots $(89-97 \mathrm{~cm})$ in this container than that in pot $(67-89 \mathrm{~cm})$ and tray $(53.7-56.7 \mathrm{~cm})$ systems. Naturally better root proliferation in trough contributed to the higher yield in this system. Lowest yields were observed for all three media when used with the tray system due to the poor root development observed in tray system. The average loss of nutrient laden water through drainage was also less in trough growing system with cocopeat+gravel+ silex stone $\left(2138.6 \mathrm{~m}^{3} / \mathrm{ha}\right)$ than tray $\left(2615.56 \mathrm{~m}^{3} / \mathrm{ha}\right)$ and pot system $\left(2286.67 \mathrm{~m}^{3} / \mathrm{ha}\right)$ with all media combinations. More over trough growing system facilitates better lateral development of roots and improved vegetative growth of plants due to the longer continuous medium ( $3 \mathrm{~m}$ length) than tray $(0.60 \mathrm{~m})$ and pot $(0.30 \mathrm{~m})$. All the above facts have attributed to the better yield in trough growing system with media of cocopeat+gravel +silex stone than the other two growing systems and media combinations.

The relatively high productivity in all hydroponic treatments indicated good scope for its adoption in highly urbanized and populated cities like Coimbatore.

\subsection{Fruit Quality Characteristics}

\subsubsection{Total Soluble Solids}

TSS ( ${ }^{\circ}$ Brix) content of fruit is an indication of sweetness and maturity of the fruit and it is a measure of the total soluble solids (TSS) in the juice of the produce. Total soluble solids refers not only to sucrose (sugar) but also to fructose, vitamins, minerals, amino acids, proteins, hormones, and other solids found in the plant, fruit or vegetable. The higher the TSS or Brix value, the healthier and more nutrient/mineral rich the plant or produce is. The plants with high Brix value will emit different UV light patterns and electrical charges which communicate to insects that they should stay away. Hence high brix plants simply do not contract fungus and disease problems. Low brix levels are equated with poorly grown crops, poor mineralization and nutriture. Good brix levels (generally above 12) also ensure improved taste, longer shelf-life and better yields.

In this study, it is well observed from data of TSS content (Table 4) that all hydroponic treatments produced high brix value fruits. The highest TSS $\left(12.5^{\circ} \mathrm{brix}\right)$ was recorded for the treatment $\mathrm{T} 4$ (trough with cocopeat+gravel+Silex stone) followed by T6 (trough with cocopeat+perlite+silex stone) and T5 (trough with cocopeat+pebble+silex stone) with values 10.9 and $10.5^{\circ}$ brix respectively. The lowest $\left(8.3^{\circ}\right.$ brix $)$ was recorded for the treatment T1 (tray with cocopeat+gravel+silex stone). Among the different growing systems, trough systems recorded highest range of (10.5-12.5) brix values followed by pot (8.9-10.3) and tray (8.3-9.4). The TSS values are significantly influenced by growing system, media and interaction comparison at 5\% level of significance. The high brix values might be due to the regular and constant availability of high EC $(2.8-3 \mathrm{ds} / \mathrm{m})$ nutrient solution towards the fruiting stage. The best values of TSS in trough growing system might be due to the less leaching of nutrient solution compared to pot and tray system. Magan et al. ${ }^{12}$ reported that increasing salinity improved various fruit quality such as total soluble solid, high visual quality etc. Gul and Sevgian ${ }^{13}$ reported highest TSS in greenhouse tomato using 1:1 peat and sand combination as growing media. Manipulation of nutrient solution electrical conductivity (EC) is a well known technique to grow flavor enhanced tomato because the elevated salinity in the nutrient solution restricts the water transport

Table 4. Effect of growing system and media TSS ( ${ }^{\circ}$ Brix) content of fruit

\begin{tabular}{lc}
\hline Treatment & TSS $\left({ }^{\circ}\right.$ Brix $)$ \\
\hline T1-Tray+cocopeat+gravel+silex stone & 8.3 \\
T2-Tray+cocopeat+pebble+silex stone & 8.7 \\
T3-Tray+cocopeat+perlite+silex stone & 9.4 \\
T4-Trough+cocopeat+gravel+silex stone & 12.5 \\
T5-Trough+cocopeat+pebble+silex stone & 10.5 \\
T6-Trough+cocopeat+perlite+silex stone & 10.9 \\
T7-pot+cocopeat+gravel+ silex stone & 9.7 \\
T8-pot+cocopeat+pebble+ silex stone & 8.9 \\
T9-pot+cocopeat+perlite+silex stone & 10.3 \\
Mean &
\end{tabular}


to fruits and thus increase the TSS value ${ }^{14-17}$. This might be the same reasons to achieve high TSS values in all hydroponic treatments. The high TSS values obtained in this experiment are also in conformity with the above mentioned results.

\subsubsection{Fruit Colour Values}

The colour and appearance of products are the first quality attributes to inspire us to purchase, consume and enjoy them. Tomatoes are known for their vibrant red colour which indicates the maturity and the relative content of antioxidant lycopene. Lycopene is the pigment principally responsible for the characteristic deep red color of ripe tomato fruits and tomato products. According to Brandt et al. ${ }^{18}$ significantly higher lycopene content was observed in glasshouse-grown tomato compared to field grown at different harvesting times. The $\mathrm{a}^{*}$ value corresponds to the degree of redness whereas the $b^{*}$ value represents yellowness and Luminance $\left(L^{*}\right)$ forms the vertical axis, which indicates whiteness to darkness. The fruit colour values are presented in Table 5. The $\mathrm{a}^{*}$ and $\mathrm{L}^{*}$ values are significant with respect to the growing system, media and interaction comparison. The $\mathrm{b}^{*}$ values and $\mathrm{a}^{*} / \mathrm{b}^{*}$ values are non-significant with respect to media and interaction comparison, but significant with respect to growing system at 5\% level of significance. Almost all hydroponic treatments recorded $\mathrm{a}^{*} / \mathrm{b}^{*}$ values approximately one. When Minolta $\mathrm{a}^{*} / \mathrm{b}^{*}$ values of tomatoes reached $>0.95$, they are found to be in the red maturity stage ${ }^{19}$. So they can be marketed easily. All hydroponic treatment showed $\mathrm{a}^{*} / \mathrm{b}^{*}$ values greater than 0.95 in this study. The highest $\mathrm{a}^{*} / \mathrm{b}^{*}$ value (1.123) was recorded for T8 (pot growing media with cocopeat+pebble+silex stone) and lowest (0.983) for T3 (tray with ocopeat+perlite+silex stone). The maximum $\mathrm{a}^{*}$ value was shown by $\mathrm{T} 1$ (tray with gravel based media) and T4 (trough with gravel based media) with values 37.97 and 37.90 respectively. $L^{*}$ values were highest for T4 (44.45) followed by T7 (pot with pebble based media) with a value of 44.10 .

\subsection{Economics of Tomato Cultivation in Aggregate Hydroponics}

The gross return, net return and benefit cost $(\mathrm{B} / \mathrm{C})$ ratio of different hydroponic treatments of tomato are presented in Table 6. All perlite based hydroponic treatments had relatively high cost of cultivation due to the high cost of the synthetic perlite medium. Though there was not much variation in the cost of cultivation of different hydroponic treatments (except the perlite based growing system), the growing system and the media exhibited significant effect on the gross return. The maximum gross (Rs.61078.5) and net return (Rs.4800.5) was obtained for the

Table 5. Effect of growing system and media on fruit colour values

\begin{tabular}{|c|c|c|c|c|c|}
\hline \multicolumn{2}{|c|}{ Treatment } & $\mathrm{L}^{*}$ & $\mathrm{a}^{*}$ & $\mathbf{b}^{*}$ & $\mathrm{a}^{*} / \mathrm{b}^{*}$ \\
\hline \multicolumn{2}{|c|}{ T1-Tray+cocopeat+gravel+silex stone } & 37.41 & 37.97 & 37.96 & 1.00 \\
\hline \multicolumn{2}{|c|}{ T2-Tray+cocopeat+pebble+silex stone } & 42.50 & 34.50 & 34.55 & 0.997 \\
\hline \multicolumn{2}{|c|}{ T3-Tray+cocopeat+perlite+silex stone } & 35.48 & 34.49 & 35.05 & 0.983 \\
\hline \multicolumn{2}{|c|}{ T4-Trough+cocopeat+gravel+silex stone } & 44.45 & 37.90 & 35.37 & 1.073 \\
\hline \multicolumn{2}{|c|}{ T5-Trough+cocopeat+pebble+silex stone } & 39.51 & 36.60 & 33.53 & 1.090 \\
\hline \multicolumn{2}{|c|}{ T6-Trough+cocopeat+perlite+silex stone } & 38.72 & 35.95 & 33.52 & 1.100 \\
\hline \multicolumn{2}{|c|}{ T7-pot+cocopeat+ gravel+silex stone } & 44.10 & 33.10 & 31.03 & 1.083 \\
\hline \multicolumn{2}{|c|}{ T8-pot+cocopeat + pebble + silex stone } & 41.38 & 34.83 & 31.25 & 1.123 \\
\hline \multicolumn{2}{|c|}{ T9-pot + cocopeat + perlite + silex stone } & 42.92 & 35.94 & 33.18 & 1.086 \\
\hline \multicolumn{2}{|l|}{ Mean } & 40.72 & 35.70 & 33.94 & 1.059 \\
\hline \multirow[t]{2}{*}{ G } & S.Ed & 0.378 & 0.328 & 0.710 & 0.028 \\
\hline & $\mathrm{CD}(0.05)$ & 0.800 & 0.695 & 1.506 & 0.059 \\
\hline \multirow[t]{2}{*}{ M } & S.Ed & 0.378 & 0.238 & 0.710 & 0.028 \\
\hline & $\mathrm{CD}(0.05)$ & 0.800 & 0.695 & NS & NS \\
\hline \multirow[t]{2}{*}{ GXM } & S.Ed & 0.654 & 0.568 & 0.710 & 0.048 \\
\hline & $\mathrm{CD}(0.05)$ & 1.386 & 1.203 & NS & NS \\
\hline
\end{tabular}


Table 6. Economics of tomato cultivation in different hydroponic treatments

\begin{tabular}{lcccc}
\hline Treatment & $\begin{array}{c}\text { Cost of cultivation } \\
\left(\mathrm{Rs}^{-1}\right)\end{array}$ & $\begin{array}{c}\text { Gross return } \\
\left(\mathrm{Rs}^{-1} \mathbf{h a}^{-1}\right)\end{array}$ & $\begin{array}{c}\text { Net return } \\
\left(\mathrm{Rs}^{-h^{-1}}\right)\end{array}$ & $\begin{array}{c}\text { Benefit cost ratio } \\
(\mathrm{B} / \mathrm{C} \text { ratio })\end{array}$ \\
\hline T1-Tray+cocopeat+gravel+silex stone & 10361.15 & 38641.5 & 28280.35 & 3.73 \\
T2-Tray+cocopeat+pebble+silex stone & 10376.23 & 34902.0 & 24525.77 & 3.36 \\
T3-Tray+cocopeat+perlite+silex stone & 11510.4 & 37395.0 & 25884.60 & 3.25 \\
T4-Trough+cocopeat+gravel+silex stone & 13073.0 & 61078.5 & 48005.5 & 4.67 \\
T5-Trough+cocopeat+pebble+silex stone & 13111.0 & 48613.5 & 35502.5 & 3.71 \\
T6-Trough+cocopeat+perlite+silex stone & 15908.0 & 52353.0 & 36445.0 & 3.29 \\
T7-pot+cocopeat+gravel+ silex stone & 10422.0 & 46120.5 & 35698.5 & 4.43 \\
T8-pot+cocopeat+pebble+ silex stone & 10445.5 & 39888.0 & 29442.5 & 3.82 \\
T9-pot+cocopeat+perlite+silex stone & 12146.0 & 42381.0 & 30235.0 & 3.48 \\
\hline
\end{tabular}

treatment T4 (trough with cocopeat, gravel and silex stone). Similarly the highest (4.67) B/C ratio was also obtained for the same hydroponic treatment T4. This high value may be due to the low cost of media, structure and the high yield of tomato. Though the treatment T6 (trough with cocopeat, perlite and silex stone) produced relatively high gross return, the net return and hence the $\mathrm{B} / \mathrm{C}$ ratio was less compared to $\mathrm{T} 4$ due to the high cost of synthetic growing media perlite. Though the yield was less in T5 (trough with pebble based media) compared to T4 it produced relatively better net return (Rs.35502.5) and $\mathrm{B} / \mathrm{C}$ ratio (3.71). The treatment $\mathrm{T} 3$ (tray with cocopeat, pelite and silex stone) exhibited lowest $\mathrm{B} / \mathrm{C}$ ratio (3.25) though the gross return was Rs.37395. This was due to the relatively high cost of cultivation and low yield in T3. However all the hydroponic treatment showed $\mathrm{B} / \mathrm{C}$ ratio more than three. Soilless cultures have been successfully used for several decades with the aim to intensify production and reduce $\operatorname{cost}^{20}$. Hence hydroponics could be recommended for commercial production of vegetables to increase the productivity.

\section{Conclusion}

The maximum yield $(4.9 \mathrm{~kg} / \mathrm{plant})$ was recorded for the treatment trough with cocopeat+gravel+silex stone (T4). The highest productivity obtained from the treatment T4 was $245.3 \mathrm{t} / \mathrm{ha}$. The treatment T2 (tray with cocopeat + pebble+silex stone) yielded least $(2.8 \mathrm{~kg} / \mathrm{plant})$ with a productivity of $138.3 \mathrm{t} / \mathrm{ha}$. The highest total soluble solids $\left(12.5^{\circ}\right.$ brix) was recorded for the treatment $\mathrm{T} 4$ and the lowest ( $8.3^{\circ}$ brix) for the treatment $\mathrm{T} 1$ (tray with cocopeat+gravel+silex stone). Regarding colour values all hydroponic treatment showed $\mathrm{a}^{*} / \mathrm{b}^{*}$ values greater than 0.95 indicating full maturity. $\mathrm{L}^{*}$ value was also highest for $\mathrm{T} 4$ (44.45). The highest $\mathrm{B} / \mathrm{C}$ ratio (4.67) was obtained for the same treatment T4. Regarding productivity, quality and economics, the treatment (T4) trough with cocopeat+gravel+silex stone performed the best and hence it can be adopted for commercial production of tomato in hydroponics under naturally ventilated polyhouse.

\section{Acknowledgement}

This research was supported by Precision Farming Development Centre, Dept of SWCE, College of Agricultural Engineering and Research Institute, Tamil Nadu Agricultural University, Coimbatore.

\section{References}

1. Charles H, Godfray J. Food and biodiversity. Science. 2011; 333:1231.

2. Tognoni F, Pardossi A, Serra G. Strategies to match greenhouses to crop production. Acta Hort. 2001; 481:451-61.

3. Tyson RV, Hochmuth RC, Lamb EE, Hochmuth GH, Sweat MS. A decade of change in Florida's greenhouse vegetable industry: 1991-2001. Proc Fla State Hort Soc. 2001; 113:280-82.

4. Bunt AC. Media and mixes for container-grown plants. 1st Edn. Springer, London; 1988.

5. Awang Y, Shaharom AS, Mohamad RB, Selamat A. Chemical and physical characteristics of cocopeat-based media mixtures and their effects on the growth and development of Celosia cristata. Am J Agr Biol Sci. 2009; 4(1):63-71.

6. Islam S. Evaluating performance of ecologically sound organic substrates under different temperature regimes. Int J Agric Biol. 2008; 10:297-300. 
7. Jensen MH. Controlled environment agriculture in deserts, tropics and temperateregions - a world review. Supported by CEAC, the Controlled Environment Agricultural Center, College of Agriculture and Life Sciences, and the University of Arizona; 2010.

8. Maher M, Prasad M, Raviv M. Organic soilless media components. In Soilless culture: Theory and practice, M. Raviv and J. H. Lieth (Eds.), Elsevier, Amsterdam; 2008.

9. Lopez-Medina J, Perablo A, Flores F. Closed soilless system growing: A sustainable solution to strawberry crop in Huelva (Spain). Acta Hort. 2004; 649:213-15.

10. Neocleous D, Polycarpou P. Gravel for soilless tomato culture in the Mediterranean Region. International Journal of Vegetable Science. 2010; 16:148-59

11. Raviv M, Lieth J. Soilless culture: theory and practice, Elsevier Science Ltd; 2008.

12. Magan JJ, Gallardo M, Thompson RB, Lorenzo P. Effects of salinity on fruit yield and quality of tomato grown in soil-less culture in greenhouses in Mediterranean climatic conditions. Agr Water Manag. 2008; 2602:1-15.

13. Gul A, Sevgican A. Suitability of various soilless media for long term greenhouse tomato growing. Acta Hort. 1994; 366:437-44.
14. Adams P. Effects of increasing the salinity of the nutrients solution with major nutrients or sodium chloride on the yield, quality and composition of tomato grown in rockwool. J Hort Sci. 1991; 66:201.

15. Mitchell JP, Shennan C, Grattan SR. Developmental changes in tomato fruit composition in response to water deficit and salinity. Physiol Planta. 1991; 83:177-85.

16. Cornish PS. Use of high electrical conductivity of nutrients solution to improve the quality of salad tomatoes grown in hydroponic culture. J Expt Agr. 1992; 32:513-20.

17. Lin WC, Glass ADM. The effects of $\mathrm{NaCl}$ addition and macronutrient concentration on fruit quality and flavor volatiles of greenhouse tomatoes. Acta Hort. 1999; 481:487-91.

18. Brandt S, Lugasi A, Barna E, Hovari J, Pek Z, Helyes L. Effects of the growing methods and conditions on the lycopene content of tomato fruits. Acta Alim. 2003; 32:269-78.

19. Batu A. Determination of acceptable firmness and colour values of tomatoes. J Food Eng. 2004; 61:471-75.

20. Maloupa EI, Mitsios P, Martinez F, Bladenopoulou S. Study of substrates used in Gerbera culture in plastic greenhouse. Acta Hort. 1993; 323:139-44. 